\title{
O USO DAS TECNOLOGIAS MÓVEIS NA EDUCAÇÃO: UMA EXPERIÊNCIA COM O ED PUZZLE
}

\author{
Evandro Lombardi, Raquel Rosan Christino Gitahy
}

Universidade do Oeste Paulista - UNOESTE, Programa de Mestrado em Educação, Presidente Prudente, SP. E-mail. lombardicpb@gmail.com. Agência de fomento: CAPES/PROSUP

\begin{abstract}
RESUMO
É fato notório o grande papel que os recursos tecnológicos têm adquirido em nossa sociedade. Hoje, os smartphones são largamente utilizados, facilitando todos os aspectos da vida cotidiana, tendo se tornado quase que extensão de nossos corpos. Assim, de suma importância mostra-se sua inserção no processo de ensino e aprendizagem, especialmente ao se considerar que os jovens alunos nasceram e cresceram numa sociedade tecnológica. Apresentamos assim, um relato de experiência envolvendo o aplicativo para smartphone ED Puzzle, que proporciona ao professor a utilização de vídeos para incrementar seu plano de ensino. O aplicativo possibilita ao professor que edite vídeos selecionados, inserindo questões a serem respondidas pelos alunos através de seus próprios celulares. Por fim, através da análise da percepção da turma com respeito a utilização do aplicativo, conclui-se a importância da disseminação do uso das tecnologias da educação.
\end{abstract}

Palavras-chave: Tecnologias Móveis, Smartphone, ED Puzzle

\section{THE USE OF MOBILE TECHNOLOGIES IN EDUCATION: AN EXPERIENCE WITH ED PUZZLE.}

\begin{abstract}
It is a remarkable fact that technological resources have acquired great importance in our society. Today, smartphones are widely used, facilitating every aspect of everyday life, having become almost an extension of our own bodies. Thus, its insertion in the teaching and learning process is extremely important, especially considering that the young students were born and grew up in a technological society. We present an experience report on the ED Puzzle smartphone application, which provides the teacher with the use of videos to increase their educational plan. The application allows the teacher to edit the selected videos, inserting questions so the students can answer through their own cell phones. Finally, through the analysis of the perception of the class regarding the use of the application, it is concluded the importance of the dissemination of the use of technologies in education process.
\end{abstract}

Keywords: Mobile Technology, smartphone, ED Puzzle 


\section{INTRODUÇÃO}

As tecnologias móveis têm, hoje em dia, presença constante dentro e fora da sala de aula. A proximidade com a tecnologia que os alunos possuem deve ser aproveitada pelos professores em prol de um aperfeiçoamento do processo de ensino e aprendizagem. Todos os anos, centenas de novos programas e aplicativos são desenvolvidos com objetivos de envolverem os alunos no processo educativo, servindo como ferramentas de aprendizado, além de diminuírem a carga de trabalho dos professores.

As tecnologias permitem que os estudantes e professores usem seus dispositivos móveis, em especial os smartphones e tablets, em sala de aula, de várias maneiras, seja para realizar pesquisas rápidas, acessar conteúdos e aplicativos educacionais ou formar grupos em redes sociais com o intuito de compreender o conteúdo de maneira compartilhada. Existe ainda a possibilidade de que a compreensão dos estudantes seja feita através de atividades avaliativas em seus próprios dispositivos.

As tecnologias educacionais também podem ser usadas para dar mais tempo para o professor, permitindo que o conteúdo que se deseja trabalhar ou revisar seja feito fora do horário de aula. Além disso, o professor pode utilizar-se dos métodos avaliativos disponíveis em diversos aplicativos, executando questionários capazes de fornecer resultados imediatos. Leite (2015) afirma que o uso das tecnologias digitais na educação é tão importante quanto o foi o quadro e o giz no passado. Além disso, conforme Kenski (2012), elas ampliam o processo de ensino e aprendizagem para além do espaço escolar.

Com a atenção dos estudantes voltadas para os conteúdos a medida que se tornam mais conectados aos seus smartphones, as tecnologias se tornam uma ponte entre professores e estudantes.

Este artigo apresenta um relato de experiência utilizando o aplicativo ED Puzzle como uma ferramenta eficaz no auxílio da compreensão dos conteúdos apresentados pelo professor e que permite ao mesmo avaliar o aprendizado dos estudantes.

\section{METODOLOGIA}

Em uma turma do 3 Ano do Ensino Médio, com 35 alunos, de uma escola particular no município de Ivatuba - PR, na disciplina de Química, foi utilizado o aplicativo ED Puzzle, permitindo ao estudante que reveja os conteúdos, constituindo uma ferramenta para aplicar as tarefas escolares com acompanhamento e avaliação pelo professor.

Esta experiência foi possível tendo em vista a aprovação Ética do CEP/CONEP da Plataforma Brasil sob o número 64459417.8.0000.5515 em 17 de fevereiro de 2017.

O ED Puzzle utiliza vídeos que podem ser obtidos diretamente do YouTube ou outro vídeo qualquer, inclusive pode ser gravado pelo próprio professor ou estudantes. A ferramenta permite que se faça a seleção de um fragmento do vídeo que seja de interesse do professor e sobre esse fragmento sejam inseridas notas de áudio, questões ou comentários que serão vistos/ouvidos durante a execução do vídeo pelos estudantes.

O primeiro passo foi acessar a página do aplicativo, no endereço: www.edpuzzle.com, e realizar a inscrição como professor no aplicativo, informando o nome da escola e a disciplina que leciona. O processo é bem simples e intuitivo, embora esteja disponível somente em língua inglesa.

O próximo passo foi clicar no menu "My classes" e criar a turma a lecionar. O professor, se desejar, pode adicionar quantas turmas for necessário (vide figura 1). Para cada turma criada é gerado um código que deverá ser apresentado ou enviado por e-mail para os estudantes. 
Figura 1. Criação das turmas no ED Puzzle

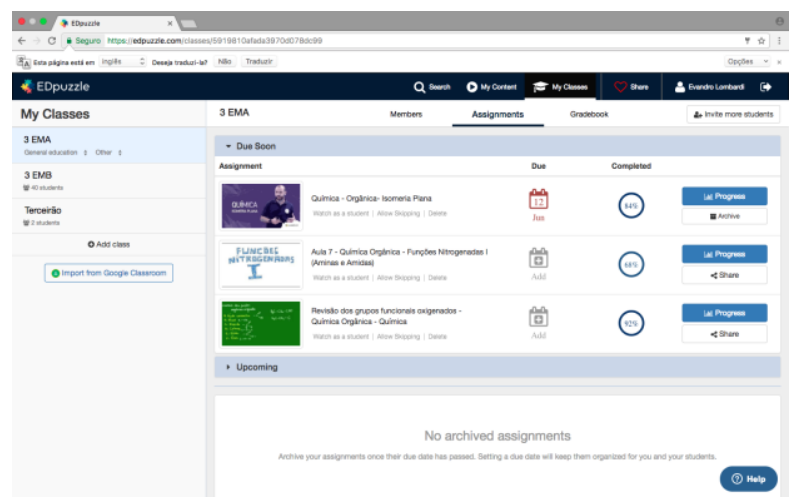

Em seguida, clicamos em "search" no menu para escolher um vídeo. Poderíamos escolher o vídeo de um banco de vídeos bem farto, que já estão pré-selecionados ou buscar outros vídeos, em diversas plataformas como o YouTube, Khan Academy, National Geographic, entre outras. Para nossa primeira atividade escolhemos uma vídeo aula já existente e de domínio público encontrada no YouTube com o tema sobre as funções orgânicas oxigenadas, tema este abordado em sala aula. O vídeo foi baixado e ficou disponível para edição na plataforma do ED Puzzle.

Uma vez escolhido o vídeo, e aberto para edição (vide figura 2), recortamos o fragmento do vídeo que desejávamos usar, inserimos comentários de voz e texto e, ao longo do vídeo, apresentamos questões para serem respondidas pelos estudantes enquanto assistiam o mesmo.

Figura 2. Edição do vídeo no ED Puzzle

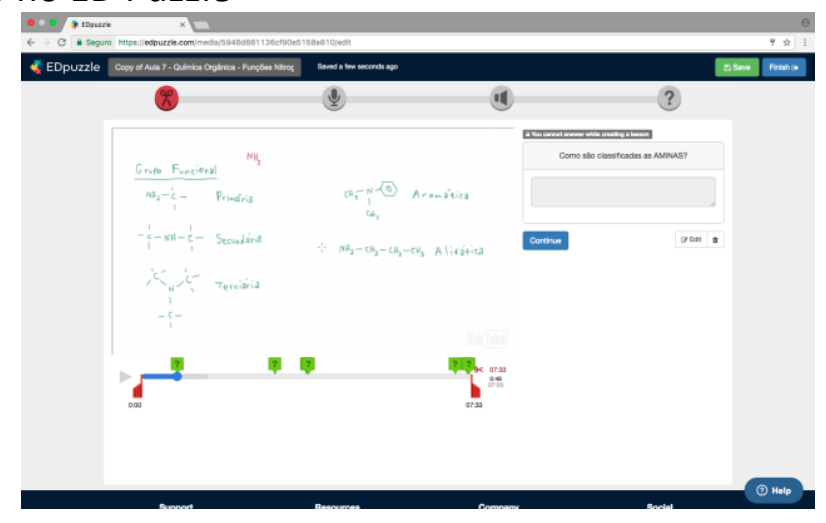

Após terminar a edição, clicamos em "save" e o vídeo foi salvo. Em seguida, clicamos em "finish" ele ficou disponível para ser enviado para a turma criadas com a opção de definir a data e horário para que a atividade se inicie e termine.

O próximo passo foi convidar os estudantes. Após orientações de como proceder para o download do aplicativo para seus smartphones e criar uma conta no mesmo, foi apresentado a eles o código da sala criada. Ao acessarem o aplicativo, abriu-se um espaço onde inseriram o código recebido e puderam assistir ao vídeo e responder as questões formuladas a partir de seus próprios smartphones. A atividade proposta foi a de uma revisão do conteúdo apresentado em sala e a tarefa escolar eram as questões propostas durante a vídeo aula apresentada.

Após os estudantes assistirem e responderem as questões, obtemos um relatório das atividades desenvolvidas. Este relatório traz (vide figura 3 ), entre outras coisas, quantas vezes o estudante assistiu cada segmento do vídeo. Se deixou de assistir alguma parte e as respostas dadas para as questões inseridas no vídeo. Corrigimos as questões e o aplicativo mensurou as atividades. 
Figura 3. Relatório individual no ED Puzzle

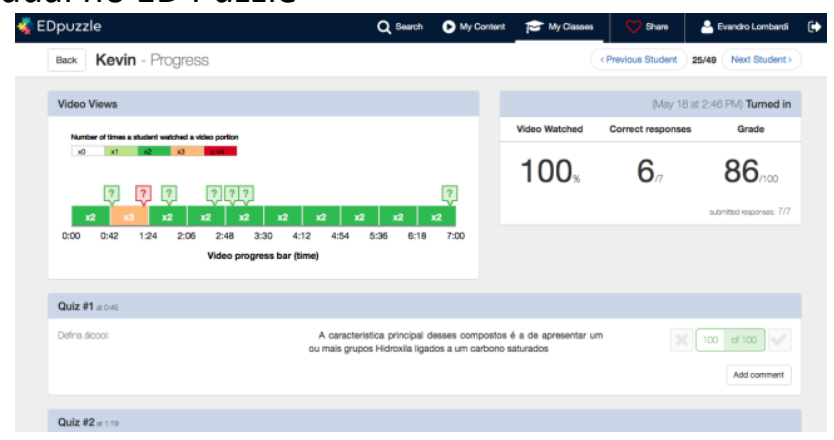

O aplicativo informa ainda, a porcentagem dos estudantes que realizaram a atividade dentro do prazo estipulado.

$\mathrm{Na}$ aula seguinte, foi discutido com os estudantes a utilização do aplicativo para reforço dos conteúdos ministrados em sala de aula e para a realização das tarefas escolares.

\section{RESULTADOS}

Após o desenvolvimento da atividade pode-se identificar um interesse maior dos estudantes quanto ao tema apresentado em sala de aula. Verificou-se que os alunos passaram a compreender melhor os assuntos abordados como na fala de Kevin": "Acaba ficando fácil para aprender, muito mais fácil do que com o acesso apenas por apostilas e caderno".

As atividades realizadas com o uso do smartphone despertaram o interesse dos estudantes, fato este claramente notado pelo envolvimento e participação deles durante as aulas seguintes.

A oportunidade de realizar atividades em que podem utilizar o dispositivo que os acompanha em todos os momentos do dia, proporciona a construção não só de conhecimentos, como habilidades e atitudes. Percebeu-se um esforço maior para as resoluções das atividades propostas e, consequentemente um melhor aproveitamento nas avaliações.

\section{DISCUSSÃO}

Após as atividades, os estudantes opinaram sobre a utilização do aplicativo. A totalidade dos estudantes concordaram que se sentiram mais estimulados a realizarem as tarefas escolares por poderem utilizar seus smartphones. Marina afirmou que realizar as atividades utilizando seu smartphone era "muito útil porque assim posso aprender com uma interatividade que gosto de usar a qualquer hora de qualquer lugar". Ou como disse Antônia: "É muito mais fácil. Tu não dependes de estar em casa para poder estudar ou estar dentro da sala de aula". Gabriel concorda ao afirmar que "Fica tudo mais prático e rápido fazendo tudo o smartphone e disponibiliza várias formas de aprender: escrita, áudios, vídeos, etc."

Outro ponto levantado pelos estudantes, quanto ao uso das tecnologias, foi o da facilidade em acessar as informações. Thomas comenta: "Acredito que além de provocar curiosidade ao aluno por estar em uma plataforma diferente do acostumado, esse método pode despertar gosto pela matéria, aprofundamento de conhecimentos e conta além disso com a praticidade e fácil acessibilidade de informações".

O poder utilizar seu smartphone para realizar as atividades escolares, ressaltando a possibilidade de aprender onde quer que estejam, é também comemorado pelos estudantes. Kevin afirma que aprender com as novas tecnologias é "muito útil porque assim posso aprender com uma interatividade que gosto de usar a qualquer hora e em qualquer lugar", e Jhow concorda

\footnotetext{
${ }^{1} \mathrm{O}$ nome dos alunos é fictício. Na pesquisa foi apresentado a possibilidade de escolherem um nome pelo qual seriam mencionados. 
com Kevin ao afirmar que o dispositivo móvel "te ajuda bastante, em qualquer lugar tu pode manusear, e quando tu vai estudar ele te ajuda nas pesquisas etc".

Os smartphones se tornaram no objeto central na construção da identidade dos jovens (CASTELLS et al., 2009). Estes se apropriam das tecnologias digitais móveis com muita rapidez e facilidade, pois diariamente as usam para os mais variados tipos de atividades.

\section{CONCLUSÕES}

A popularização do uso das tecnologias móveis na sociedade possibilita que as informações cheguem a um maior número de pessoas em qualquer hora e lugar. Dessa forma, se apresenta como uma ótima ferramenta para melhorar o processo de ensino e aprendizagem. Gera um sentimento de empoderamento no estudante por ficar em uma posição ativa e relevante no processo educativo. Ao se moldarem os conteúdos e o apresentarem em aplicativos que podem ser acessados por seus smartphones, o estudante apropria-se da informação com mais facilidade .

A comunicação é um elemento importante para a construção do conhecimento, proporcionando o desenvolvimento cognitivo dos estudantes, independente das tecnologias ou meios utilizados (SILVA; SARTORI e SPANHOL, 2013). Porém, com a utilização das tecnologias se incrementam as possibilidades de interações entre os atores, há melhoria na comunicação e, dessa forma, se derruba a barreira que separa estudantes e professores, tornando o processo educativo mais prazeroso.

Vemos um estudante mais próximo de uma sociedade híbrida, onde se sobrepõe o digital e o real. Os indivíduos se sentem conectados e parte de seu próprio aprendizado.. Já não são meros espectadores do espetáculo mas construtores colaborativos do conhecimento.

Graças a mobilidade digital e a sensação de pertencer ao ambiente educativo, a formação permanente, a educação, a cultura, tudo sempre a mão, transforma-se a sociedade, as formas de aprender e os sentimentos dos atores de todo o processo, tornando-se cada vez mais produtivos.

Os usuários apropriam-se da tecnologia e com ela, de toda a informação, entendendo a importância de exercer sua responsabilidade como membro ativo de uma comunidade de aprendizagem.

\section{REFERENCIAS}

CASTELLS, M. et al. Mobile Communication and Society: A Global Perspective. Cambridge: MIT Press, 2009.

LEITE, B. S. Tecnologias no Ensino de Química: Teoria e prática na formação docente. Curitiba, Appris, 2015.

SILVA, A. R. L. da. SARTORI, A. S. SPANHOL, F. J. Convergência das mídias na Educação a Distância: Tessituras Plurais. In: BIEGING, P.; et al. (Org.) Tecnologia e novas mídias: da educação às práticas culturais e de consumo. São Paulo: Pimenta Cultural, 2013.

KENSKI, V.M. Educação e Tecnologias: o novo ritmo da informação. Campinas, Papirus, 2012. 